\title{
Correspondence
}

\section{Intraoperative stimulation of the P6 point controls postoperative nausea and vomiting following laparoscopic surgery}

To the Editor:

One of the most promising non-pharmacologic techniques to prevent postoperative nausea and vomiting (PONV) has been the use of transcutaneous electrical nerve stimulation of the $\mathrm{P} 6$ point. ${ }^{1-3}$

The purpose of the present study was to determine whether stimulation of the P6 point with train-of-four (TOF) mode of the conventional peripheral nerve stimulator (PNS), from induction of anesthesia until the reversal of residual neuromuscular blockade, is efficacious in controlling PONV following laparoscopic procedures without compromising monitoring of neuromuscular block.

Following Board-of-Studies permission and written consent of the patient, 42 ASA I and II female patients undergoing elective laparoscopic procedures lasting 60 to $90 \mathrm{~min}$ were selected without considering phase of menstrual cycle. The patients were randomly divided into two groups of 21 each. In patients of Group C [control: $34.2 \pm 10.5 \mathrm{yr} ; 54.4 \pm 6.0 \mathrm{~kg}$ ], TOF monitoring was achieved by the conventional placement of the electrode of the PNS (TOF-Watch, Organon Ltd., Dublin, Ireland) along the ulnar nerve. In patients of Group S (study: $32.7 \pm 11.7 \mathrm{yr} ; 54.3 \pm 4.6$ $\mathrm{kg}$ ), the cathode of the PNS was placed at the P6 point, ${ }^{4}$ while the anode was placed $5 \mathrm{~cm}$ apart, more proximally (Figure). This stimulates the median nerve, a site recommended for TOF monitoring. ${ }^{5}$

Anesthesia was standardized. A blinded observer recorded episodes of PONV for the next 24 postoperative hours. Ten milligrams of metoclopramide were administered intramuscularly as rescue antiemetic.

A paired t test was used to compare the incidence of PONV. $P<0.05$ was considered significant.

The incidence of PONV in the control group was $52.4 \%(11 / 21)$, which was greater than the $28.6 \%$ $(6 / 21)$ incidence observed in the study group. All 11 patients of the control group except one had PONV within the first six postoperative hours. On the contrary, all six patients of the study group had a first episode of PONV after the first six hours. Furthermore, study group patients needed only one (mean) dose of metoclopramide to control PONV

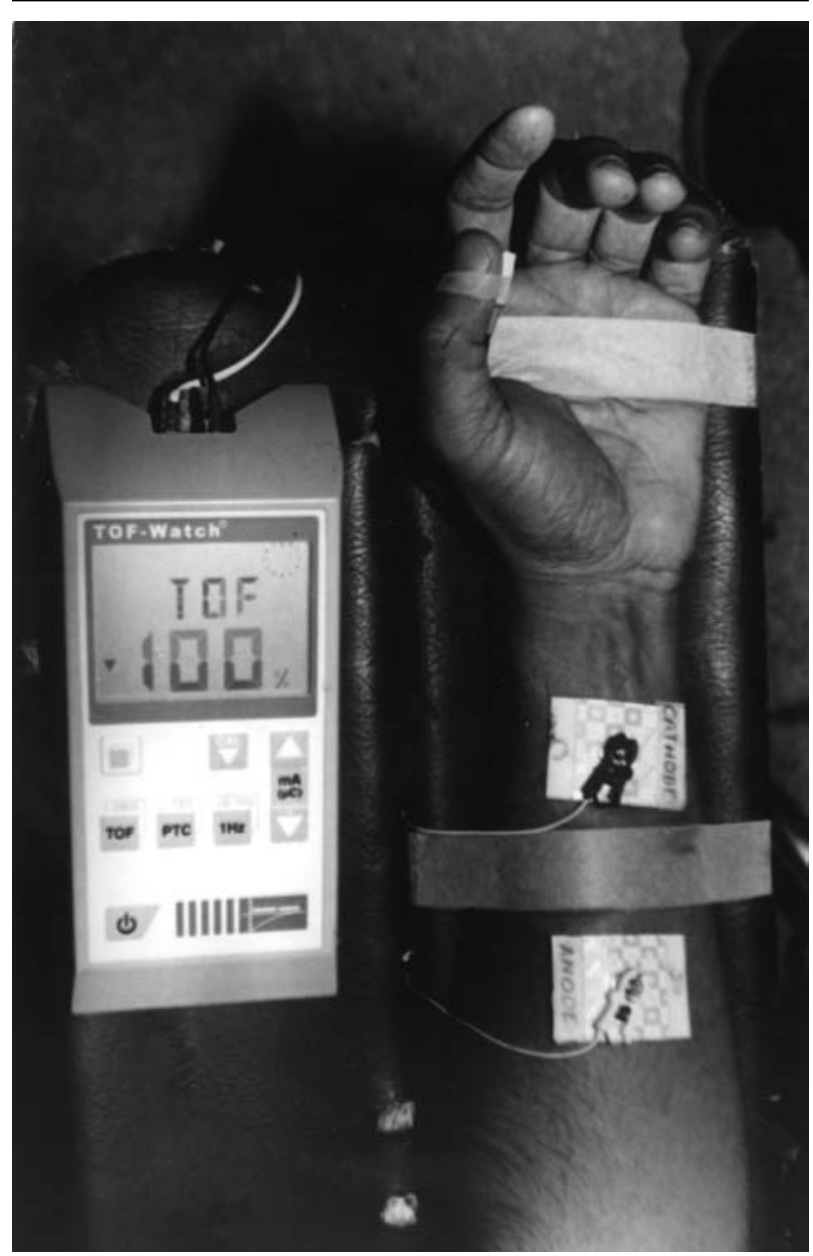

FIGURE Cathode of the peripheral nerve stimulator at the P6 point (situated between the tendons of the flexor carpi radialis and palmaris longus, 2 Chinese inches from the distal crease) and the anode placed $5 \mathrm{~cm}$ apart, more proximally.

over the first $24 \mathrm{hr}$ as compared to 2.4 doses in the control group. The probable mechanism of action of P6 stimulation in controlling PONV is due to the release of neurotransmitters in the brain. ${ }^{2,3}$

In conclusion, our study suggests that P6 stimulation using PNS not only reduces the incidence of PONV following laparoscopic surgery, but also reduces the antiemetic requirement needed to control PONV without affecting TOF monitoring of the neuromuscular blockade: a two-in-one use of the PNS. 
Rashid M. Khan MD*

Mohammed Maroof MD†

Seema Hakim MD*

Divya Jain MBBS*

Moin Ashraf DA*

Aligarh, India*

Charlotte, North Carolina $†$

\section{References}

1 Lee A, Done ML. The use of nonpharmacologic techniques to prevent postoperative nausea and vomiting: a meta-analysis. Anesth Analg 1999; 88: 1362-9.

2 Fassoulaki A, Papilas K, Sarantopoulos C, Zotou M. Transcutaneous electrical nerve stimulation reduces the incidence of vomiting after hysterectomy. Anesth Analg 1993; 76: 1012-4.

3 Stein DJ, Birnbach DJ, Danzer BI, Kuroda MM, Grunebaum A, Thys DM. Acupressure versus intravenous metoclopramide to prevent nausea and vomiting during spinal anesthesia for cesarean section. Anesth Analg 1997; 84: 342-5.

4 Rowbotham DJ. Nausea, vomiting and their treatment. In: Aitkenhead AR, Rowbotham DJ, Smith G (Eds). Textbook of Anaesthesia, 4th ed. Edinburgh: Churchill Livingstone; 2001: 244-9.

5 Dorsch JA, Dorsch SE. Neuromuscular transmission monitoring. In: Dorsch JA, Dorsch SE (Eds). Understanding Anesthesia Equipment, 4th ed. Baltimore: Williams \& Wilkins; 1998: 849-92.

\section{More on regional anesthesia induction rooms}

To the Editor:

I would like to comment on a recent editorial on the interest of an induction room. ${ }^{1}$ Basically, the creation of an induction room involves four issues: quality of anesthesia care; functioning costs; timing of patient management; and benefits for teaching.

Cost issues involve the salary of a medical assistant and expenses related to running an additional "operating" room. However, when the patient is successfully blocked, his/her stay in the operating room is shortened as induction is eliminated, and there are no additional anesthetic expenses. The anesthesiologist remains available for the next block procedure and after surgery, the patient can bypass the recovery room, saving money, occupational time and a bed. Thus, a functioning induction room represents a transfer of activity rather than new activity.
In institutions doing mostly local anesthesias (no required "soak" time for block installation) or when regional techniques are occasional, an induction room is of lesser interest. Conversely, when the load of conduction block patients is heavy, an induction room allows optimizing the occupation time of up to three operating rooms. Performing a plexus block requires approximately $30 \mathrm{~min}$ (equipment/medication set-up, procedure and clean up): up to 16 patients per-eight hour day can be treated. When adding the time for block installation (30 min, no staff assistance required), one hour of operating room time can be spared for each successfully blocked patient.

Lastly, an induction room is more suited for teaching regional anesthesia than can be a busy operating room with awaiting surgeons.

Bernard Dalens MD

Sainte-Foy, Québec

\section{Reference}

1 Drolet P, Girard M. Regional anesthesia, block room and efficiency: putting things in perspective (Editorial). Can J Anesth 2004; 51: 1-5.

\section{Peripheral oxygen saturation falls in the lateral lumbar puncture position}

To the Editor:

In the lateral lumbar puncture (LLP) position, patients are asked to bend forward as much as possible. This can restrict chest wall movement and provoke hypoxemia. However, little has been reported on the changes in partial pressure of arterial oxygen or peripheral oxygen saturation $\left(\mathrm{SpO}_{2}\right)$ in the LLP position. ${ }^{1,2}$ We observed the changes in $\mathrm{SpO}_{2}$ using a pulse oximeter (N-395, Nellcor Puritan Bennett Inc., Pleasanton, CA, USA) during the time 60 patients (ASA physical status I-IV, 19-78 yr, 21 male and 39 female) assumed the LLP position. We also investigated whether the administration of oxygen $\left(3 \mathrm{~L} \cdot \mathrm{min}^{-1}\right)$ prevents $\mathrm{SpO}_{2}$ decrease.

Before the day of surgery, we measured the changes in $\mathrm{SpO}_{2}$ when the patients were in the sitting, supine and LLP positions in the ward. Patients were divided into two groups: a low group (lowest $\mathrm{SpO}_{2}$ less than $97 \%, n=34$ ) and a high group (lowest $\mathrm{SpO}_{2}$ equal to or more than $97 \%, n=26$ ). In the operating room, the low group patients received oxygen $\left(3 \mathrm{~L} \cdot \mathrm{min}^{-1}\right)$ by nasal cannulae during spinal and/or epidural puncture. 